\title{
Features and impact of missing values in the association of self-rated health with mortality in care homes: a longitudinal study
}

María del Pilar Rodríguez-García ${ }^{1}$, Alba Ayala², Carmen Rodríguez-Blázquez³, Pablo Martínez-Martín³, Maria João Forjaz ${ }^{2^{*}}$ and Javier Damián ${ }^{3}$

\begin{abstract}
Background: Self-rated health (SRH) is a health measure used in studies of older adults. The objective of this study is to analyze SRH as a predictor of mortality in the institutionalized older population and the characteristics of those who do not provide information about their SRH on health questionnaires.

Methods: This is a 15-year follow-up study of older adult residents in nursing or care homes in of Madrid, Spain. SRH was measured on a 5-point Likert type scale. The association between answering the SRH question and sociodemographic and health characteristics was evaluated through prevalence ratio (PR), estimated by Poisson regression models. Survival rates associated with SRH were studied through a multivariate Cox regression.

Results: The sample has a mean age of 83.4 (standard deviation, SD =7.3), with 75.7\% women. Twelve percent did not answer the SRH item. Those who did not answer showed a higher probability of disability (Barthel index, PR= $0.76,95 \%$ confidence interval $=0.67-0.86)$ and/or dementia $(P R=8.03,3.38-19.03)$. A trend for higher mortality was observed in those persons who did not respond (adjusted hazard ratio $H R=1.26,0.75-2.11$ ). The mortality rate was $32 \%$ higher for those who declared poor SRH in comparison with those who reported good SRH (adjusted HR= 1.32, 1.08-1.6).

Conclusions: There is an elevated number of people who do not respond to the SRH item, mainly those with disabilities and cognitive deterioration. Lack of response to SRH is a good indicator of 15-year mortality for persons institutionalized in care or nursing homes.
\end{abstract}

Keywords: Self-rated health, Mortality, Care and nursing homes, Elderly people, Missing values

\section{Background}

Self-rated health $(\mathrm{SRH})$ is the rating that individuals give to their health status. It is a global measure both of mental state and of physical condition [1]. In 1982, Mossey and Shapiro considered SRH as a predictor of mortality among the older population [2]. Since then, it has frequently been used as an indicator of health and as a predictor of mortality or survival in both the general and older population [3], as it is an easy, low-cost and

\footnotetext{
* Correspondence: jforjaz@isciii.es

${ }^{2}$ National School of Public Health, Institute of Health Carlos III and REDISSEC,

Avda Monforte de Lemos 5, 28029 Madrid, Spain

Full list of author information is available at the end of the article
}

convenient measure and has been widely validated [4]. It has been recommended as an indicator by the World Health Organization since 1996 for its ability to evaluate mortality, morbidity, functional state, and disability and, consequently, enable effective management of health resources [5].

The ability of SRH to predict the survival of individuals depends on the insight that they have of their own state of health [1]. This situation can explain the variations in SRH as a mortality predictor across distinct population groups, such as by social and cultural class, and by age [1]. As an example, older people have a higher probability of suffering potentially fatal events,

(c) The Author(s). 2019 Open Access This article is distributed under the terms of the Creative Commons Attribution 4.0 International License (http://creativecommons.org/licenses/by/4.0/), which permits unrestricted use, distribution, and reproduction in any medium, provided you give appropriate credit to the original author(s) and the source, provide a link to the Creative Commons license, and indicate if changes were made. The Creative Commons Public Domain Dedication waiver (http://creativecommons.org/publicdomain/zero/1.0/) applies to the data made available in this article, unless otherwise stated. 
which are not taken into account in the perception of their health status. This is because the baseline health status for these people (prior to the adverse event) is lower, which contributes to a weaker association between SRH and mortality at more advanced ages [1].

On the other hand, there are various studies that suggest that the relation between SRH and mortality is significantly weaker when models adjust for other health indicators $[3,6]$. Disability or chronic health conditions can be determinant factors for individuals in rating their own health status. Similarly, symptoms of depression or cognitive problems can play an important role [1, 7], both in the general population and in institutionalized people in care or nursing homes [8].

Other studies have explored SRH as a factor associated with survival in specific populations, as is the case with people suffering from dementia [9]. In these cases, people with greater cognitive deterioration may be incapable of evaluating their own health status, which entails a limitation for the analysis [10].

The majority of longitudinal studies on SRH has a follow-up period of between 6 and 9 years [3], and some cover even shorter periods. It is worthwhile studying whether SRH maintains an effective role as a measure of health and predictor of survival over longer follow-up periods. Furthermore, most of the studies that relate SRH and mortality usually use surveys on noninstitutionalized population [11, 12], which has a better health status than institutionalized older adults. Our study fills this research gap by focusing on the institutionalized population.

As a consequence, in this study our objective is to study SRH as a predictor of survival in a cohort of institutionalized older people in Madrid for a 15 year followup period. In addition, as a second objective, we analyse the frequency of "no response" and the characteristics of the individuals who do not respond to the SRH questionnaire and study their mortality.

\section{Methods}

\section{Design and participants}

A retrospective cohort study was carried out on a sample of 699 people over 65 years old, who lived in care and nursing homes in Madrid, with a 15-year maximum follow-up.

We selected a baseline probabilistic sample of residents, aged 65 years and over, of public and private nursing homes in the city of Madrid (Spain) and a surrounding area of up to $35 \mathrm{~km}$ distant. Study participants were selected through stratified cluster sampling, including one stratum with 22 public and 25 subsidized (privately owned but publicly funded) nursing homes and another stratum with 139 private institutions. As a first stage, we sampled 25 public/subsidized and 30 private institutions with probability proportional to their sizes. As a second stage the interviewers obtained a list of all the residents from the director of each facility and then they selected 10 men and 10 women in each public/subsidized facility chosen and five men and five women from each private nursing home chosen by means of a systematic sampling with random start (with the aid of random number tables). Four private institutions (totalling 40 sample subjects) refused participation and 45 additional residents could not be selected due to absence or refusal, leading to an overall response rate of $89 \%$ (715 of the 800 sample residents). Due to refusal, prolonged absence or sampling frame errors, 39 subjects were randomly replaced with residents of the same facility and sex, with the consequence that information could be gathered through structured interviews with 754 residents. Of the 754 participants in the baseline survey, 55 with unknown vital status on termination of follow-up were excluded leaving a study sample of 699 people.

\section{Assessments}

All-cause mortality was considered as a main endpoint. Mortality was ascertained by reference to the Spanish National Death Index provided by the Ministry of Health and, in addition, information regarding deaths was obtained from the survey completed by the facilities in 2013 [13]. The baseline data were collected via structured questionnaires between June 1998 and June 1999. These questionnaires were administered by trained interviewers to the residents, medical personnel from the facility, and the principal carer. Socioeconomic information were also collected by the interviewers.

SRH was assessed in the interview administered to the residents via the question "in general terms, how would you rate your health?" The response was collected through a scale with five response options: very good, good, moderate, bad or very bad. Afterwards these were grouped into two categories: good SRH ("very good" and "good") and bad SRH ("moderate", "bad" and "very bad").

The presence of 20 chronic health conditions associated with higher mortality, including chronic pulmonary obstructive disease (COPD), heart failure, diabetes and cancer as well as diagnosis of depression were evaluated through interviews with the medical staff in the facility.

Functional capacity was explored through the Barthel index, as modified by Shah et al. [14], with a rating from 0 to 100 . Those residents with scores from 61 to 99 were classified as having a mild or moderate dependence, and 0-60 as severe or total dependence [14]. Information on the Barthel index activities was collected by interviewing the residents' main caregiver (49\%) or the residents themselves when they did not have a caregiver assigned (51\%). Data about the cognitive state of the residents were collected indirectly with a question on the 
dementia, which includes diagnosis of Alzheimer-type dementia and/or other dementias identified in the interview with physician. The presence of pressure ulcers was informed by the physicians [15].

\section{Data analysis}

A descriptive analysis of the data was carried out to study the distribution of socio-demographic variables in the sample (age, sex, marital status, level of education), the presence of chronic problems (COPD, heart failure, diabetes and cancer), and other health indicators (depression, disability, cognitive state and SRH).

We investigated the distribution of chronic problems and health indicators in the residents, grouped by whether or not they answered the SRH question. Subsequently, a multivariate Poisson regression was carried out to measure the association, expressed in prevalence ratios (PR), between the sociodemographic and health variables, and the variable known/unknown SRH. The variables included in the model were age; sex; the presence of pressure ulcers (at the moment of interview); the Barthel index; educational level; and chronic health problems (depression, dementia, COPD, diabetes, cancer, heart failure and others). Finally, survival was analysed for this variable (known/unknown SRH) with a multivariate Cox regression model - in this case adjusted for the same variables present in the Poisson regression model.

Furthermore, 15-year survival was examined in relation to having good or bad SRH. For this, Cox regression model was employed, in this case adjusting for sociodemographic and health variables. We used age instead of follow-up as time scale. A person's follow-up time depends on the age at which he or she entered the study. Therefore, it was not necessary to adjust the model for this variable. In addition, there are authors who recommend the use of age as a time scale in studies of older people [16, 17]. This model presented $22 \%$ of missing data, fundamentally as a result of the SRH variable, but also from other variables. To reduce the probability of selection bias related to this relatively high proportion of missing data, a multiple imputation by chained equations was carried out. This substituted the values of the missing data with a set of simulated values [18]. The model complied with assumption of proportional hazards.

At every stage we used sample weights to re-establish proportionality, and the analysis was carried out considering the complex sampling design. STATA 14 was used to carry out the analysis.

\section{Results}

The 699 individuals who made up the sample had a mean age of 83.4 (standard deviation, $\mathrm{SD}=7.3$ ) years at the start of the study (Table 1), 24.3\% were men, $14.0 \%$ had partners and $14.7 \%$ had finished their secondary education or had higher level studies. Almost half lived in public institutions (47\%). Over the 15-year follow-up period 598 participants died, which was $84.7 \%$ of the total.

According to the baseline data, the participants had a mean (SD) of 3.2 (2.1) chronic health problems. Chronic pulmonary disease had a prevalence of $19.1 \%$ and congestive heart failure 19.7\%. Almost one fifth (19.4\%) of the sample had been diagnosed with depression, and $31.2 \%$ had dementia. Pressure ulcers were recorded for $3.0 \%$ whereas $22.1 \%$ of the participants were totally independent in the activities of daily living. Of the participants, $48.1 \%$ declared their perception of health to be good; $12 \%$ of participants did not answer.

The results of the multivariate study regarding the characteristics of participants who did not answer the SRH question, expressed as PR, are shown in Table 2. A relationship with disability and dementia can be seen, with a PR of 0.76 and 8.03. That is to say, for every increase of 10 points on the Barthel index, the probability of unknown SRH reduces by $24 \%$.

Figure 1 shows the Kaplan-Meier curve for crude mortality in relation to SRH known and unknown (Hazard Ratio, $\mathrm{HR}=1.77$; confidence interval, $95 \% \mathrm{CI}=1.18$ 2.67). The adjusted value obtained in the Cox regression was $\mathrm{HR}=1.26(95 \% \mathrm{CI}=0.75-2.11)$. In other words, those who did not respond to the SRH had a slightly higher risk of dying, although it was not statistically significant at the $5 \%$ level.

Finally, Table 3 shows the results of the multivariate Cox regression in relation to SRH (good vs bad). Poor SRH increased the risk of death by $32 \%$, adjusted for sociodemographic variables and for health variables. Using the imputed data, the risk of death for people with poor SRH decreased to $26 \%$.

\section{Discussion}

The construct of SRH has been considered a good predictor of survival in several population groups, like in the over-18 Estonian population [19], or in North Americans over $70[20,21]$. In this study we have investigated the predictive role of SRH in a cohort of institutionalized people in Madrid over a follow-up period of 15 years. People with poor SRH had a greater risk of death than those who reported good SRH.

\section{Characteristics of those who did not respond to the questionnaire}

In our study we noted that $12 \%$ of participants did not answer the SRH question. Other studies have reported values of $18 \%$ [20, 21] and 69\% [4]. These studies, most of them performed on non-institutionalized population, considered that people who did not answer the SRH 
Table 1 Descriptive analysis

\begin{tabular}{|c|c|c|c|c|c|c|c|c|}
\hline \multicolumn{3}{|c|}{ Sociodemographic characteristics } & \multicolumn{3}{|c|}{ Health problems } & \multicolumn{3}{|l|}{ Health markers } \\
\hline & $\mathrm{n}^{\mathrm{a}}$ & $\%^{\mathrm{b}}$ & & $\mathrm{n}^{\mathrm{a}}$ & $\%^{\mathrm{b}}$ & & $\mathrm{n}^{\mathrm{a}}$ & $\%^{\mathrm{b}}$ \\
\hline Total & 699 & $100 \%$ & COPD & & & Depression & & \\
\hline Sex & & & No & 520 & $80.0 \%$ & No & 546 & $77.2 \%$ \\
\hline Male & 313 & $24.3 \%$ & Yes & 172 & $19.1 \%$ & Yes & 131 & $19.4 \%$ \\
\hline Female & 386 & $75.7 \%$ & Unknown & 7 & $1.0 \%$ & Unknown & 22 & $3.4 \%$ \\
\hline Educational level & & & $\mathrm{CHF}$ & & & Disability & & \\
\hline Primary or less & 551 & $75.7 \%$ & No & 548 & $78.2 \%$ & Independent (100) & 187 & $22.1 \%$ \\
\hline Secondary and higher & 95 & $14.7 \%$ & Yes & 137 & $19.7 \%$ & Mild/moderate (61-99) & 316 & $47.0 \%$ \\
\hline Unknown & 53 & $9.6 \%$ & Unknown & 14 & $2.1 \%$ & Severe/total (0-60) & 179 & $28.5 \%$ \\
\hline Civil status & & & Diabetes & & & Unknown & 17 & $2.5 \%$ \\
\hline With couple & 122 & $14.0 \%$ & No & 561 & $81.3 \%$ & Dementia & & \\
\hline Without couple & 553 & $81.9 \%$ & Yes & 135 & $18.3 \%$ & No & 494 & $67.8 \%$ \\
\hline Unknown & 24 & $4.1 \%$ & Unknown & 3 & $0.4 \%$ & Yes & 198 & $31.2 \%$ \\
\hline Type of residence & & & Cancer & & & Unknown & 7 & $1.0 \%$ \\
\hline Public & 401 & $47.0 \%$ & No & 629 & $90.8 \%$ & Self-rated Health & & \\
\hline Subsidized & 72 & $8.0 \%$ & Yes & 66 & $8.7 \%$ & Good & 336 & $48.1 \%$ \\
\hline Private & 226 & $45.1 \%$ & Unknown & 4 & $0.6 \%$ & Bad & 292 & $39.9 \%$ \\
\hline Dead at 15 years & & & Pressure ulc & & & Unknown & 71 & $12.0 \%$ \\
\hline No & 81 & $12.1 \%$ & No & 677 & $97.0 \%$ & & Mean ${ }^{b}$ & $S D^{b}$ \\
\hline Yes & 598 & $84.7 \%$ & Yes & 22 & $3.0 \%$ & Age & 83.4 & 7.3 \\
\hline Unknown & 20 & $3.2 \%$ & Unknown & 0 & $0 \%$ & $\mathrm{CHP}$ & 3.2 & 2.1 \\
\hline
\end{tabular}

a Observed frequencies; ${ }^{\mathrm{b}}$ Weighted estimators; SD Standard deviation, CHP Chronic health problems, COPD Chronic obstructive pulmonary disease, CHF Congestive heart failure

question had worse health but did not describe their characteristics.

We found a higher mortality in people who did not report their SRH when compared to those who did answer the SRH question in the questionnaire. Not responding to $\mathrm{SRH}$ was related to disability (the greater the degree of disability the higher the prevalence of nonrespondents) and to the presence of dementia. This indicates that the non-respondents to the SRH question do have poorer health, which corresponds with previous

Table 2 Factors associated with unknown self-rated health (multivariate Poisson regression)

\begin{tabular}{llll}
\hline Variable & & PR & $\mathrm{Cl}(95 \%)$ \\
\hline Sex (ref. female) & & 0.25 & $(0.10-0.63)$ \\
Age (ref. 65-74 years) & $75-84$ & 0.13 & $(0.04-0.45)$ \\
& $\geq 85$ & 0.11 & $(0.005-0.28)$ \\
Educational level (ref. primary or less) & Secondary and higher & 0.68 & $(0.22-2.13)$ \\
Pressure ulcer (ref. No) & & 1.15 & $(0.64-2.07)$ \\
Disability (Barthel index) & $\geq 2$ & 0.76 & $(0.67-0.86)$ \\
CHP (ref. <2) & & 0.94 & $(0.75-1.33)$ \\
Dementia (ref. No) & & 8.03 & $(3.38-19.03)$ \\
Depression (ref. No) & 0.59 & $(0.23-1.47)$ \\
COPD (ref. No) & 0.90 & $(0.51-1.58)$ \\
Cancer (ref. No) & 0.97 & $(0.48-1.95)$ \\
Diabetes (ref. No) & 0.68 & $(0.33-1.41)$ \\
CHF (ref. No) & 0.45 & $(0.18-1.14)$
\end{tabular}

$P R$ Prevalence ratio, $\mathrm{Cl}$ Confidence interval, ref. Reference category, COPD Chronic obstructive pulmonary disease, CHF Congestive heart failure, CHP Chronic health problems (excluding COPD, CHF, cancer, diabetes, dementia and depression) 


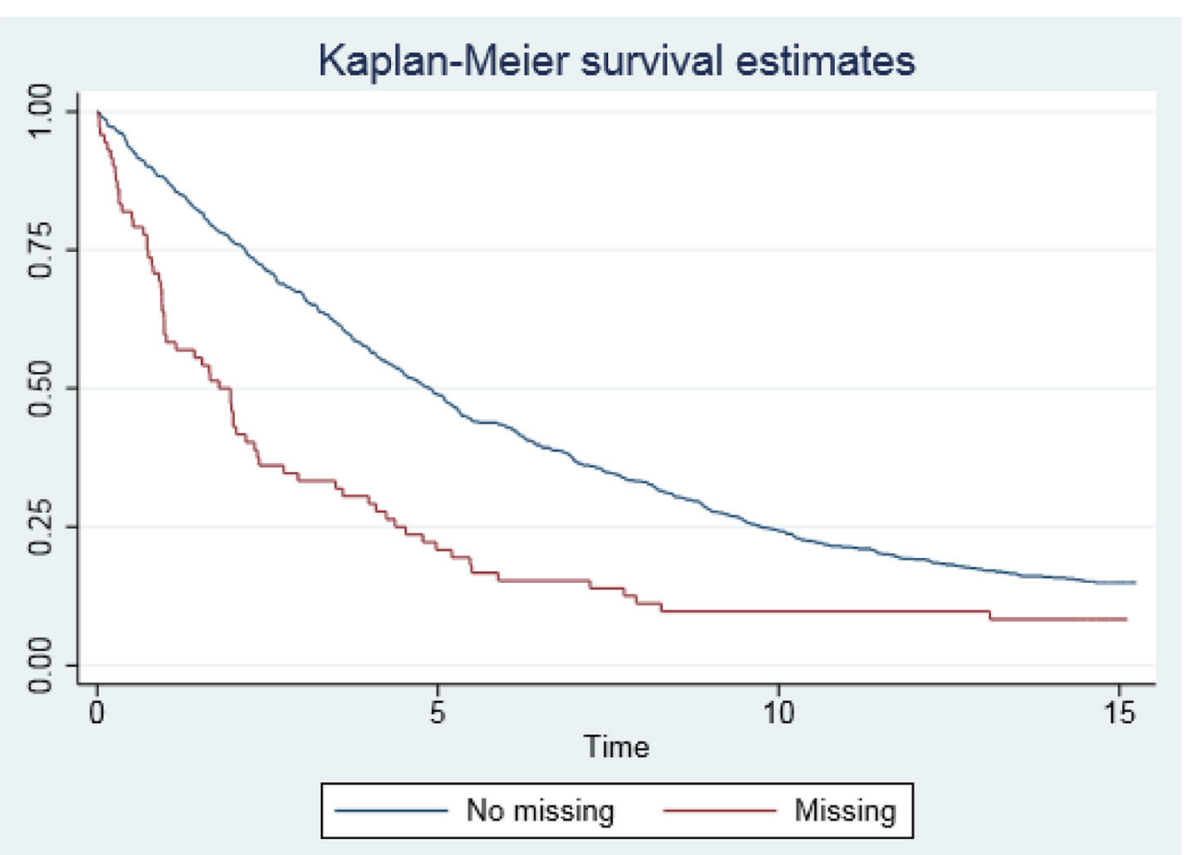

Fig. 1 Kaplan-Meier curve for crude mortality relative to reply or not the item self-rated health questionnaire

studies [22]. The non-adjusted mortality risk for nonrespondents to this item was higher than for those who did respond. However, in the adjusted model this association was weaker. This suggests that the mortality risk related to answering or not responding to the question is due to, for the most part, disabilities and the presence of cognitive deterioration.

The limitation entailed by cognitive deterioration and the presence of dementia for answering self-report questions in surveys has already been confirmed [23]. There

Table 3 Survival based on self-rated health according to the final multivariate Cox regression model including health markers

\begin{tabular}{|c|c|c|c|c|c|c|c|}
\hline \multirow{2}{*}{ Variable } & & \multicolumn{3}{|c|}{ Observed model $(N=534)$} & \multicolumn{3}{|c|}{ Imputed model $(N=699)$} \\
\hline & & $\mathrm{HR}$ & $\mathrm{Cl}(95 \%)$ & $p$-value & $\mathrm{HR}$ & $\mathrm{Cl}(95 \%)$ & $p$-value \\
\hline Self-rated health (ref. Good) & $\mathrm{Bad}$ & 1.32 & $(1.08-1.60)$ & 0.007 & 1.26 & $(1.04-1.53)$ & 0.019 \\
\hline Sex (ref. Female) & Male & 1.07 & $(0.85-1.35)$ & 0.539 & 1.02 & $(0.84-1.24)$ & 0.842 \\
\hline Educational level (ref. Primary or less) & Secondary and higher & 0.89 & $(0.63-1.26)$ & 0.491 & 0.91 & $(0.66-1.28)$ & 0.588 \\
\hline Civil status (ref. With couple) & Without couple & 1.16 & $(0.84-1.61)$ & 0.361 & 1.08 & $(0.81-1.46)$ & 0.584 \\
\hline \multirow[t]{2}{*}{ Type of residence (ref. Public) } & Subsidized & 0.87 & $(0.71-1.07)$ & 0.187 & 0.82 & $(0.63-1.07)$ & 0.132 \\
\hline & Private & 0.72 & $(0.54-0.96)$ & 0.028 & 0.73 & $(0.55-0.97)$ & 0.032 \\
\hline Pressure ulcer (ref. No) & Yes & 2.44 & $(1.19-5.02)$ & 0.017 & 2.81 & $(1.61-4.88)$ & 0.001 \\
\hline \multirow[t]{2}{*}{ Disability (ref. Independent) } & Mild/moderate & 1.25 & $(0.98-1.58)$ & 0.067 & 1.31 & $(1.06-1.62)$ & 0.013 \\
\hline & Severe/total & 1.99 & $(1.39-2.84)$ & $<0.001$ & 1.98 & $(1.52-2.58)$ & $<0.001$ \\
\hline Depression (ref. No) & Yes & 0.65 & $(0.49-0.87)$ & 0.004 & 0.66 & $(0.51-0.85)$ & 0.002 \\
\hline Dementia (ref. No) & Yes & 0.85 & $(0.61-1.18)$ & 0.312 & 1.12 & $(0.84-1.49)$ & 0.421 \\
\hline COPD (ref. No) & Yes & 1.30 & $(0.98-1.74)$ & 0.071 & 1.36 & $(1.07-1.73)$ & 0.015 \\
\hline Cancer (ref. No) & Yes & 1.20 & $(0.80-1.79)$ & 0.364 & 1.23 & $(0.92-1.64)$ & 0.158 \\
\hline CHF (ref. No) & Yes & 1.38 & $(1.08-1.78)$ & 0.012 & 1.38 & $(1.08-1.77)$ & 0.012 \\
\hline Diabetes (ref. No) & Yes & 1.39 & $(1.00-1.92)$ & 0.048 & 1.22 & $(0.94-1.59)$ & 0.129 \\
\hline CHP (ref. <2) & $\geq 2$ & 0.79 & $(0.58-1.07)$ & 0.123 & 0.82 & $(0.65-1.04)$ & 0.104 \\
\hline
\end{tabular}

CHP Chronic health problems, COPD Chronic obstructive pulmonary disease, CHF Congestive heart failure, $\mathrm{Cl}$ Confidence Interval, $H R$ Hazard ratio, ref Reference category 
is an association between the level of cognitive deterioration and the proportion of non-responders to selfadministered questionnaires (missing data). When there is a high level of missing data, this is considered as study limitation [24] because it hinders the results interpretation.

On the other hand, in the case of our study, people with disability, independently of their cognitive ability, had higher levels of non-response to the SRH question. Nevertheless, the relationship between disability and nonresponse to self-administered questionnaires is less studied. Generally, studies based on questionnaires usually have disability, especially cognitive, as an exclusion criterion, or a requirement that any disability should be minimal $[25,26]$. This means that the selected samples are biased [27]. Therefore, authors like Paula Diehr recommend including all sample members as far as possible [28].

\section{Other variables related to higher mortality}

In the final regression model of this study, the relationship of SRH to mortality was adjusted by other variables related to chronic processes, sociodemographic variables, and health indicators. Some of these variables are also associated with lower survival rates. The characteristics that were related to higher mortality were residing in a public facility rather than in a private one, the presence of pressure ulcers, disability, and heart failure.

Pressure ulcers are related to a severe deterioration in health state and with a lack of care, and thus to higher mortality [29]. Nonetheless, some studies associate this to dementia, disability or comorbidity [30]. In our case, the study has adjusted for all of these variables and the relation of pressure ulcers to mortality is independent of these. This indicates the importance that the care provided has, in order to avoid the occurrence of pressure ulcers - given that they are preventable in $98 \%$ of cases [31] - and to improve survival for these people. Indeed, the appearance of pressure ulcers is an indicator of the quality of care, as they are the most preventable and treatable complication presented by people with reduced mobility [31].

The relation of disability, depression and heart failure with mortality has been put forward in numerous studies [32-34]. In our study, these relationships were significant in both models with the observed and imputed data, respectively, which gives greater strength to our results. The finding of higher mortality for people not diagnosed with depression may be because these people are identified, diagnosed and treated unlike other people who may have undetected and untreated depression and, therefore, lower survival [35]. For another two variables, COPD and diabetes, the statistical relationship showed minimal variation between the two models (observed and imputed data). These health conditions are also associated with higher mortality in the literature, as third and fourth highest causes of death in the world [36].

Finally, in our study we found an association between higher mortality and living in a public nursing or care home. The characteristics of the home are important for the residents and the contextual factors that influence this relationship was analysed in another study about facility ownership and mortality [37].

\section{Strengths and limitations}

This study has a number of limitations, the most important of which is the quantity of missing data $(22 \%)$ at the moment of interpreting the statistical analysis. Nevertheless, the comparison between the imputed and observed data suggests that the observed data was not unduly influenced by the characteristics of the missing data. The second limitation is that the sample is only representative of older adults institutionalized in Madrid, for which reason it would be interesting to repeat the study in other institutionalized older populations. Finally, some deaths could not be identified by the study. Nonetheless, this circumstance should not affect the results of the statistical analysis, given that those missed during the follow up period would not be different, in principle, from the groups of interest.

\section{Conclusions and implications}

Our results suggest that SRH is a good indicator of mortality in persons who reside in care or nursing homes in the autonomous community of Madrid. Nevertheless, in the group of participants with the highest levels of disability and/or dementia, for whom there is a higher probability of not answering the item on the questionnaire, SRH might not be such a good predictor. This implies that, in populations with high prevalence of disability, associated or not with cognitive deterioration, the use of other markers for mortality would be more reliable than SRH.

\section{Abbreviations \\ CHF: Congestive heart failure; CHP: Chronic health problems; Cl: Confidence interval; COPD: Pulmonary obstructive disease; PR: Prevalence ratio; ref:: reference category; SD: Standard deviation; SRH: Self-rated health}

\section{Acknowledgements \\ Not applicable. \\ Disclaimer: This paper presents independent results and/or research. The views expressed are those of the authors and not necessarily those of the Instituto de Salud Carlos III (Institute of Health Carlos III).}

\section{Authors' contributions}

MPRG was a major contributor in analysing the data and writing the manuscript. AA assisted in the statistical analysis. JD is the principal investigator of the study, and had a major role in its design and data gathering. MJF designed the present data analysis and supervised the statistical analysis and manuscript writing. PMM and CRB reviewed the manuscript for important intellectual content. All authors read and approved the final manuscript. 


\section{Funding}

This work was supported by the Institute of Health Carlos III (grant number, PI15CIII00037) and partially supported by the ENCAGE-CM programme (ref: S2015/HUM-3367, co-funded by Madrid Community and FEDER). The funding bodies did not have any role in the design of the study and collection, analysis, and interpretation of data and in writing the manuscript.

\section{Availability of data and materials}

Data and material are available on reasonable request to the last author, Javier Damian (jdamian@isciii.es).

\section{Ethics approval and consent to participate}

The authors assert that all procedures contributing to this work comply with the ethical standards of the relevant national and institutional committees on human experimentation and with the Helsinki Declaration of 1975, as revised in 2008. Oral informed consent, duly documented, was obtained from all study participants or their next of kin. The Institute of Health Carlos III Institutional Review Board approved the study and waiver of written informed consent, with a reference number CEI PI 152014

\section{Consent for publication}

Not applicable.

\section{Competing interests}

The authors declare that they have no competing interests.

\section{Author details}

${ }^{1}$ Puertollano Integrated Care Management, Ciudad Real, Spain. ${ }^{2}$ National School of Public Health, Institute of Health Carlos III and REDISSEC, Avda Monforte de Lemos 5, 28029 Madrid, Spain. ${ }^{3}$ National Center of Epidemiology, Institute of Health Carlos III and CIBERNED, Madrid, Spain.

\section{Received: 2 November 2018 Accepted: 19 June 2019}

Published online: 29 June 2019

\section{References}

1. Jylhä M. What is self-rated health and why does it predict mortality? Towards a unified conceptual model. Soc Sci Med. 2009;69:307-16

2. Mossey JM, Shapiro E. Self-rated health: a predictor of mortality among the elderly. Am J Public Health. 1982;72:800-8.

3. Idler EL, Benyamini Y. Self-rated health and mortality: a review of twentyseven community studies. J Health Soc Behav. 1997;38:21-37.

4. Assari S. Gender differences in the predictive role of self-rated health on short-term risk of mortality among older adults. SAGE Open Med. 2016;4.

5. Bruin, A, Picavet, H.S.J., Nossikov, A. Health interview surveys: towards international harmonization of methods and instruments. WHO regional publications. European series; $\mathrm{N}^{\circ} 58$;

6. Wagner DC, Short JL. Longitudinal predictors of self-rated health and mortality in older adults. Prev Chronic Dis. 2014;11:E93.

7. Stanojevic Jerkovic O, Sauliune S, Sumskas L, Birt CA, Kersnik J. Determinants of sef-rated health in elderly populations in urban areas in Slovenia, Lithuania and UK: findings of the EURO-URHIS 2 survey. Eur J Pub Health. 2017;27(suppl_2):74-9.

8. Damián J, Pastor-Barriuso R, Valderrama-Gama E. Factors associated with self-rated health in older people living in institutions. BMC Geriatr. 2008:8:5

9. Nielsen AB, Siersma V, Waldemar G, Waldorff FB. Poor self-rated health did not increase risk of permanent nursing placement or mortality in people with mild Alzheimer's disease. BMC Geriatr. 2016;16:87.

10. Nilsson K, Hydbom AR, Rylander L. How are self-rated health and diagnosed disease related to early or deferred retirement? A cross-sectional study of employees aged 55-64. BMC Public Health. 2016;16:886

11. Cisleghi B, Cisleghi C. Self-rated health as a valid indicator for health-equity analyses: evidence from the Italian health interview survey. BMC Public Health. 2019;19(1)

12. Vie $T L$, Hufthammer KO, Meland E, Breidablik HJ. Self-related health (SRH) in young people and causes of death and mortality in young adulthood. A prospective registry-based Norwegian HUNT-study. SSM Popul Health. 2019; 7:100364.

13. Damián J, Pastor-Barriuso R, Valderrama-Gama E, de Pedro-Cuesta J. Discordance between physician-rated health and an objective health measure among institutionalized older people. BMC Geriatr. 2015;15:78.
14. Shah S, Vanclay F, Cooper B. Improving the sensitivity of the Barthel index for stroke rehabilitation. J Clin Epidemiol. 1989;42:703-9.

15. Damián J, Pastor-Barriuso R, García-López F, de Pedro-Cuesta J. Urinary incontinence and mortality among older adults residing in care homes. J Adv Nurs. 2017;73:688-99.

16. Lamarca R, Alonso J, Gómez G, Muñoz A. Left-truncated data with age as time scale: an alternative for survival analysis in the elderly population. J Gerontol A Biol Sci Med Sci. 1998;53:M337-43.

17. Rius Gibert C, Pérez Albarracín G, Cohesca G. Age as time-scale: an application to the survival analysis of chronic diseases. Rev Esp Salud Publica. 2006;80:657-64.

18. Hawkley LC, Kocherginsky M, Wong J, Kim J, Cagney KA. Missing data in wave 2 of NSHAP: prevalence, predictors, and recommended treatment. J Gerontol B Psychol Sci Soc Sci. 2014;69(S2):38-50.

19. Reile $R$, Stickley A, Leinsalu M. Large variation in predictors of mortality by levels of self-rated health: results from an 18-year follow-up study. Public Health. 2017:145:59-66.

20. Tamayo-Fonseca N, Barber X, Quesada JA, Nolasco A, Melchor I, Moncho J, Pereyra-Zamora P, et al. Self-rated health and mortality: a follow-up study of a Spanish population. Public Health. 2013;127:1097-104.

21. Vogelsang EM. Self-rated health changes and oldest-old mortality. J Gerontol B Psychol Sci Soc Sci. 2014;69:612-21.

22. Rodríguez Laso Á, Urdaneta Artola E, de la Fuente Sánchez M, Galindo Moreno E, Yanguas Lezáun JJ, Rodríguez Rodríguez V. Analysis of selection bias in the pilot study of a longitudinal study on aging in Spain. Gac Sanit. 2013;27:425-32

23. Anstey KJ, Luszcz MA. Selective non-response to clinical assessment in the longitudinal satudy of aging: implications for estimating population levels of cognitive function and dementia. Int J Geriatr Psychiatry. 2002;17:704-9.

24. Tan JP, Li N, Cui B, Wang LN, Zhao YM, Liu ZY, et al. Characteristics of participants' and caregivers' influence on non-response in a cross-sectional study of dementia in an older population. Arch Gerontol Geriatr. 2016;62: 143-51.

25. Val Jiménez CL, López-Torres Hidalgo J, García Atienza EM, Navarro Ruiz MS, Hernández Cerón I, Moreno de la Rosa L. Functional status, self-rated health and level of physical activity of patients with osteoarthritis [Article in Spanish]. Aten Primaria. 2017;49:224-32.

26. Fernandez-Mayoralas G, Giraldez-Garcia C, Forjaz MJ, Rojo-Perez F, MartinezMartin P, Prieto-Flores ME, et al. Design, measures and sample characteristics of the CadeViMa-Spain survey on quality of life in community-dwelling older adults. Int Psychogeriatr. 2012;24:425-38.

27. Gaskin CJ, Lambert SD, Bowe SJ, Orellana L. Why sample selection matters in exploratory factor analysis: implications for the 12-item World Health Organization disability assessment schedule 2.0. BMC Med Res Methodol. 2017:17:40.

28. Diehr P, Diehr M, Arnold A, Yee LM, Odden MC, Hirsch CH, et al. Predicting future years of life, death and functional ability: a healthy life calculator for older adults. Gerontol Geriatr Med. 2015;Jan-Dec:1-10.

29. Jaul E, Calderon-Margalit R. Systemic factors and mortality in elderly patients with pressure ulcers. Int Wound J. 2015;12:254-9.

30. Jaul E, Meiron O, Menczel J. The effect of pressure ulcers on the survival in patients with advanced dementia and comorbidities. Exp Aging Res. 2016; 42:382-9.

31. García-Fernández FP, Soldevilla-Ágreda JJ, Pancorbo-Hidalgo PL, Verdú Soriano J, López-Casanova P, Rodríguez-Palma M. Prevención de las úlceras por presión. Serie de Documentos Técnicos GNEAUPP n¹. Grupo Nacional para el Estudio y Asesoramiento en úlceras por Presión y Heridas Crónicas. Logroño; 2014.

32. Brummel NE, Bell SP, Girard TD, Pandharipande PP, Jackson JC, Morandi A et al. Frailty and subsequent disability and mortality among patients with critical illness. Am J Respir Crit Care Med. 2017;196:64-72.

33. Gilman SE, Sucha E, Kingsbury M, Horton NJ, Murphy JM, Colman I. Depression and mortality in a longitudinal study: 1952-2011. CMJA. 2017; 189: E-1304-10.

34. Shang X, Lu R, Xiao S, Dong N. Heart rate and outcomes in patiens with heart failure with preserved ejection fraction: a dose-response meta-analysis. Medicine. 2017;96:e8431.

35. Damián J, Pastor-Barriuso R, Valderrama-Gama E. de Pedro-Cuesta J. association of detected depression and undetected depressive symptoms with long-term mortality in a cohort of institutionalised older people. Epidemiol Psychiatr Sci. 2017;26:189-98. 
36. Plan de Acción Mundial para la Prevención y Control de las Enfermedades no Transmisibles 2013-2020. Organización Mundial de la Salud; 2013.

37. Damián J, Pastor-Barriuso R, García-López F, Ruigómez A, Martinez-Martin P, de Pedro-Cuesta J. Facility ownership and mortality among older adults residing in care homes. PLoS One. 2019;14:e0197789.

\section{Publisher's Note}

Springer Nature remains neutral with regard to jurisdictional claims in published maps and institutional affiliations.

Ready to submit your research? Choose BMC and benefit from:

- fast, convenient online submission

- thorough peer review by experienced researchers in your field

- rapid publication on acceptance

- support for research data, including large and complex data types

- gold Open Access which fosters wider collaboration and increased citations

- maximum visibility for your research: over $100 \mathrm{M}$ website views per year

At BMC, research is always in progress.

Learn more biomedcentral.com/submissions 